\title{
Loss of endothelium-dependent vasodilatation and nitric oxide release after myocardial protection with University of Wisconsin solution
}

\begin{abstract}
University of Wisconsin solution has proved to be a superior form of cardioplegia for cardiac transplantation, demonstrating better functional recovery than that provided by extracellular crystalloid solutions. Furthermore, experimental data have suggested a role for University of Wisconsin solution in protection of the neonatal heart during operations for congenital heart defects. However, significant concerns have been raised regarding potential endothelial injury from the high potassium concentration contained in University of Wisconsin solution that could affect its safety and thus its clinical application. Fourteen neonatal (aged 1 to 3 days) piglet hearts were harvested and supported on an isolated, blood-perfused circuit. Endothelium-dependent vasodilatation was measured by bradykinin $\left(10^{-6} \mathrm{~mol} / \mathrm{L}\right)$ infusion and nitric oxide release was determined. Endothelium-independent vasodilatation was then induced by sodium nitroprusside $\left(10^{-6} \mathrm{~mol} / \mathrm{L}\right)$ infusion. A 2-hour period of cold cardioplegic arrest was instituted with multidose University of Wisconsin solution (group 1, $n=7$ ) or blood cardioplegia (group 2, $n=7$ ). After reperfusion and stabilization, another stimulation with bradykinin and nitroprusside was carried out and nitric oxide was again measured. After 2 hours of arrest with University of Wisconsin solution, there was a near-complete loss of vasodilatation in response to bradykinin infusion; coronary blood flow reached $245 \%$ of baseline before arrest versus only $117 \%$ of baseline after arrest $(p=0.0011)$. This correlated with an inability of the endothelium to release nitric oxide $(96 \pm 30$ $\mathrm{nmol} / \mathrm{min}$ before arrest versus $-32 \pm 9 \mathrm{nmol} / \mathrm{min}$ after arrest, $p=0.0039$. In group 2 , the vasodilatory response to bradykinin was preserved after arrest and reperfusion; $265 \%$ of baseline before arrest versus $222 \%$ of baseline after arrest. These results demonstrate a loss of endothelium-dependent vasodilatation after multidose University of Wisconsin cardioplegia caused by the inability of the endothelium to release nitric oxide. In contrast, blood cardioplegia does not result in impaired endothelial function. (J ThORAC Cardiovasc SURG 1994;107:257-64)
\end{abstract}

Jeffrey M. Pearl, MD, Hillel Laks, MD, Davis C. Drinkwater, MD, Thomas J. Sorensen, BS, Paul Chang, BS, Alon S. Aharon, MD, Russell E. Byrns, MS, and Louis J. Ignarro, $\mathrm{PhD}$, Los Angeles, Calif.

From The Division of Cardiothoracic Surgery, Departments of Surgery and Pharmacology, University of California, Los Angeles, Medical School, Los Angeles, Calif.

Presented at the Sixty-fifth Scientific Sessions of the American Heart Association, New Orleans, La., Nov. 17-20, 1992.

Received for publication Jan. 8, 1993.

Accepted for publication May 17, 1993.

Address for reprints: Hillel Laks, MD, Professor and Chief, Division of Cardiothoracic Surgery, UCLA Medical Center, CHS 62-151, 10833 Le Conte Ave., Los Angeles, CA 90024.

Copyright 1994 by Mosby-Year Book, Inc.

$0022-5223 / 94 \$ 1.00+.10 \quad 12 / 1 / 49793$
$\mathrm{U}$ iversity of Wisconsin (UW) solution has proved to be a superior agent in organ preservation. ${ }^{1-3}$ Studies in cardiac transplantation have demonstrated superior functional recovery with UW solution compared with extracellular crystalloid solutions. ${ }^{4-6}$ In view of these reports, many centers (including our own) have adopted UW solution as the cardioplegic solution of choice for cardiac preservation. Furthermore, because of UW solution's clear superiority in myocardial protection for transplantation, it has been suggested that UW solution may have a role in myocardial protection for purposes other than transplantation. In particular, UW solution could be 
Table I. Composition of cardioplegic solutions

\begin{tabular}{lcc}
\hline \multicolumn{1}{c}{ Cardioplegia } & $\begin{array}{c}\text { Group I } \\
\text { (UW solution) }\end{array}$ & $\begin{array}{c}\text { Group 2 } \\
\text { (blood } \\
\text { cardioplegia) }\end{array}$ \\
\hline Sodium (mEq/L) & 132 & 133 \\
Potassium (mEq/L) & $22 / 10$ & 140 \\
Chloride (mEq/L) & 93 & 120 \\
Calcium (mmol/L) & 0.6 & Trace \\
Osmolarity (mOsm) & 333 & 320 \\
pH & 7.6 & 7.4 \\
Pentafraction (gm/L) & 50 & \\
Lactobionic acid (gm/L) & 35.8 & \\
Raffinose pentahydrate (gm/L) & 17.8 & \\
Adenosine (gm/L) & 1.34 & \\
Allopurinol (gm/L) & 0.136 & \\
Glutathione (gm/L) & 0.922 & \\
\hline
\end{tabular}

applied to the protection of the immature myocardium, which remains suboptimal with current techniques. ${ }^{7-10}$

However, increased recognition of the importance of endothelial physiology in the regulation of coronary blood flow, ${ }^{11-15}$ platelet aggregation, ${ }^{16-18}$ and prevention of atherosclerosis ${ }^{18}$ has raised concern regarding potential endothelial injury from the high potassium concentration in UW solution. Loss of vasodilatory reserve has been demonstrated after arrest and storage with high-potassium cardioplegia solutions, ${ }^{17,19-23}$ including UW solution. ${ }^{24}$ Although functional endothelial injury has been implicated as the cause of the impaired vasodilatory response, ${ }^{18}$ the specific pathways involved, including the role of nitric oxide, have been poorly defined.

\section{Materials and methods}

Hearts were removed from 14 neonatal ( 1 to 3 days old) piglets (Duroc) without intervening ischemia and placed on an isolated, blood-perfused circuit. Hearts were perfused with oxygenated arterial blood from a support animal warmed to $38^{\circ} \mathrm{C}$ by a blood cardioplegia device (BCD; Shiley, Inc., Irvine, Calif.). The blood was delivered retrogradely through the innominate artery to the aortic root at a constant pressure of 80 $\mathrm{mm} \mathrm{Hg} .{ }^{10} \mathrm{Hearts}$ were not placed in the working mode so that accurate coronary arterial and venous samples could be obtained.

After assessment of baseline coronary blood flow (collected from the pulmonary artery catheter), vasodilation was induced by instilling bradykinin mixed in blood to a final concentration of $10^{-6} \mathrm{~mol} / \mathrm{L}$. A 1 -minute infusion was given and coronary blood flow per minute was measured for 3 minutes. The average coronary blood flow measured during this period was calculated and expressed both in milliliters per gram of heart tissue and as a percentage of baseline coronary flow. New baseline flows were obtained before each intervention. In addition, a $5 \mathrm{ml}$ sample of arterial and coronary sinus blood was obtained for nitric oxide determination after the 1-minute infusion of bradykinin.

After return of coronary flow to a steady baseline, usually 30 minutes after the bradykinin infusion, blood containing sodium nitroprusside $\left(10^{-6} \mathrm{~mol} / \mathrm{L}\right)$ was infused for 1 minute and coronary blood flow was measured for 3 minutes. Once again, the average coronary blood flow per minute during this 3-minute period was used for comparison and results were expressed as percentage of baseline coronary flow. The perfusion pressure was kept constant at $80 \mathrm{~mm} \mathrm{Hg}$ throughout both series of experiments.

Hearts were then arrested with either UW solution (group 1, $n=7$ ) or blood cardioplegic solution (group 2,n=7) delivered at $50 \mathrm{~mm} \mathrm{Hg}$ until arrest and then at $40 \mathrm{~mm} \mathrm{Hg}$ (Table I). A 2-minute dose of cold cardioplegic solution was given and topical cooling with iced saline solution was also used. Repeated 2-minute doses of cold cardioplegic solution were given at 40 $\mathrm{mm} \mathrm{Hg}$ every 20 minutes. After 2 hours of cold cardioplegic arrest with multidose cardioplegia, hearts were reperfused with warm, unmodified blood. After normalization of blood flow 30 minutes after reperfusion, hearts were once again stimulated with bradykinin and then with nitroprusside in a manner identical to that before arrest. Nitric oxide samples were again obtained.

Nitric oxide analysis. After collection, whole-blood samples were immediately placed on ice and then centrifuged at $4^{\circ} \mathrm{C}$ for 10 minutes at $3200 \mathrm{rpm}$. The supernatant was removed and frozen at $-70^{\circ} \mathrm{C}$. Aliquots of $100 \mu \mathrm{l}$ were then injected into the measuring apparatus and any nitrite or nitrate was rapidly reduced to nitric oxide by vanadium (III) at $98^{\circ} \mathrm{C} . .^{25-27} \mathrm{Oxy}-$ gen-free purified nitrogen was delivered into a reaction flask and then the nitrogen flowed through the system and was drawn into the Dasibi Chemiluminescence NOx Analyzer (model 2108; Dasibi, Glendale, Calif.) at a constant rate of $200 \mathrm{ml} / \mathrm{min}$ with the aid of a vacuum pump. The detector is sensitive to nitrogen dioxide radical, the photon-emitting product generated by the reaction between ozone and nitric oxide. The analyzer was calibrated before each use with a standard mixture of $825 \mathrm{ppb}$ nitric oxide in oxygen-free nitrogen (Scott-Marrin, Inc., Riverside, Calif.). Results were expressed in nanomoles per $100 \mu$ l. The arteriovenous difference was then calculated and multiplied by the coronary blood flow to obtain a release rate of nitric oxide in nanomoles per minute.

Statistics. A paired $t$ test was used to compare the change in coronary blood flow with baseline both before and after arrest and reperfusion. A paired $t$ test was also used to compare the release of nitric oxide before and after preservation. A $p$ value of less than 0.05 was considered significant.

Animal care. All animals were cared for in compliance with the "Principles of Laboratory Animal Care" formulated by the National Society for Medical Research and the "Guide for the Care and Use of Laboratory Animals" prepared by the National Academy of Sciences and published by the National Institutes of Health (NIH Publication No. 86-23, revised 1985).

\section{Results}

Endothelium-dependent vasodilatation. Before cardioplegic arrest, there was a significant increase in coronary blood flow in response to bradykinin infusion in both groups; $245 \%$ of baseline in group 1 ( $1.29 \pm 0.26$ versus $2.88 \pm 0.77 \mathrm{ml} / \mathrm{gm}, p=0.0046)$ and $265 \%$ of baseline in group $2(1.95 \pm 0.54$ versus $4.44 \pm 1.65 \mathrm{ml} / \mathrm{gm}$, $p=0.01$; Fig. 1). After 2 hours of cardioplegic arrest, 


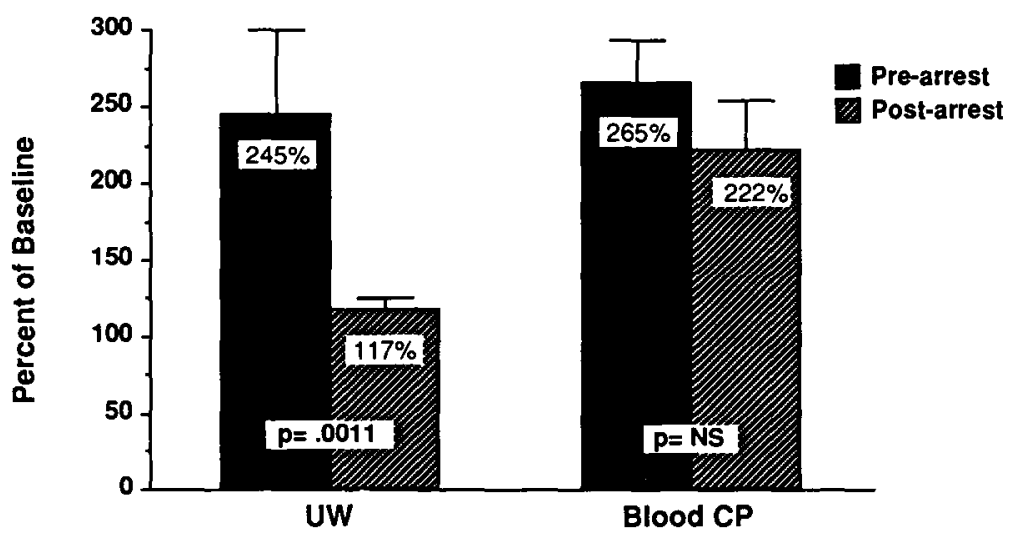

Fig. 1. Endothelium-dependent coronary blood flow. Before cardioplegic arrest, there was a significant increase in coronary blood flow with bradykinin stimulation in both group 1 and group 2, 245\% and $265 \%$ of baseline, respectively. After UW solution arrest, there was a loss of vasodilatation in response to bradykinin, reaching only $117 \%$ of baseline $(p=0.0011)$. Vasodilatory response was preserved in hearts protected with low-potassium blood cardioplegia (group 2). NS, Not significant; Blood CP, blood cardioplegia.

there was a near-complete loss of the vasodilatory response to bradykinin in hearts protected with UW solution; response reached only $117 \%$ of baseline, which was not significantly different from baseline ( $1.31 \pm 0.54$ versus $1.51 \pm 0.6 \mathrm{ml} / \mathrm{gm}, p=0.1)$. There was, however, a significant difference $(p=0.0011)$ between prearrest and postarrest response in group 1 (Fig. 1). In contrast, hearts protected with blood cardioplegic solution retained their ability for bradykinin-induced coronary artery vasodilatation; $222 \%$ of baseline after arrest versus $265 \%$ of baseline before arrest (Tables II and III).

Endothelium-independent vasodilatation. Before cardioplegic arrest, there was a significant increase in coronary blood flow in response to a 1-minute infusion of sodium nitroprusside; $186 \%$ of baseline in group 1 $(1.19 \pm 0.29$ versus $2.23 \pm 0.33 \mathrm{ml} / \mathrm{gm}, p=0.0001)$ and $222 \%$ of baseline in group $2(1.83 \pm 0.71$ versus $3.85 \pm 0.86 \mathrm{ml} / \mathrm{gm}, p=0.0001$; Fig. 2). After 2 hours of multidose cardioplegia with UW solution, the response to sodium nitroprusside was unchanged from prearrest values, reaching $173 \%$ of baseline $(1.17 \pm 0.43$ versus $2 \pm 0.71 \mathrm{ml} / \mathrm{gm}, p=0.0008$; Fig. 2). This indicates preservation of the endothelium-independent vasodilatory response. Hearts protected with blood cardioplegic solution demonstrated a small but significant $(p=0.006)$ decrease in vasodilatory response to nitroprusside after 2 hours of cardioplegic arrest, with $176 \%$ after arrest versus $222 \%$ before arrest (Tables II and IV).

Nitric oxide release. The mean nitric oxide release in response to bradykinin stimulation was $96.2 \pm 32.0$ $\mathrm{nmol} / \mathrm{min}$ in hearts in group 1 before arrest (Table III). After 2 hours of arrest with UW solution, there was a complete loss of nitric oxide release in response to brady- kinin, at $-32.7 \pm 9 \mathrm{nmol} / \mathrm{min}(p=0.0039$ compared with prearrest values; Fig. 3). This loss of nitric oxide release correlated closely with the lack of vasodilatation observed in response to bradykinin stimulation in this group after UW cardioplegic arrest.

\section{Discussion}

Donor organ availability remains the major limitation in cardiac transplantation. For this reason, more efficient use of donor hearts is necessary. Investigations into methods of preservation ${ }^{1-5,24}$ and reperfusion ${ }^{28-31}$ have resulted in improved organ function and lengthened the period of safe ischemia. ${ }^{1-3,28}$ UW solution has been shown in several laboratory and clinical studies, ${ }^{4,5}$ to result in superior functional recovery of transplanted hearts. UW solution is an intracellular solution that contains a $140 \mathrm{mEq} / \mathrm{L}$ concentration of potassium, compared with the 10 to $20 \mathrm{mEq} / \mathrm{L}$ in most extracellular crystalloid cardioplegic solutions and in blood cardioplegic solution. UW solution also contains several unique ingredients designed to decrease intracellular and interstitial edema, provide metabolic support, and scavenge oxygen-derived free radicals.

We recently demonstrated in our laboratory the ability of UW solution to protect the immature myocardium when used for multidose cardioplegia. ${ }^{32}$ In an isolated, blood-perfused working heart model, significantly improved recovery of stroke work index was obtained after 2 hours of cold cardioplegic arrest with UW solution as compared with blood cardioplegic solution. Functional recoveries were $100 \%, 86 \%, 79 \%$, and $80 \%$ at left atrial pressures of $3,6,9$, and $12 \mathrm{~mm} \mathrm{Hg}$, respectively, in hearts protected with UW solution, compared with $65 \%$ to $70 \%$ 
Table II. Coronary blood flows in milliliters per gram of heart tissue

\begin{tabular}{ccccccccc}
\hline Heart & Baseline & $\begin{array}{c}\text { Bradykinin } \\
\text { before }\end{array}$ & Baseline & $\begin{array}{c}\text { Nitroprusside } \\
\text { before }\end{array}$ & Baseline & $\begin{array}{c}\text { Bradykinin } \\
\text { after }\end{array}$ & Baseline & Nitroprusside afier \\
\hline Group 1 & & & & & & & & \\
B & 1.33 & 2.33 & 0.83 & 2.00 & 0.75 & 0.83 & 0.67 & 1.17 \\
2 & 1.45 & 2.55 & 1.32 & 2.00 & 1.18 & 1.18 & 0.91 & 2.09 \\
3 & 1.69 & 2.34 & 1.66 & 2.62 & 2.03 & 1.86 & 1.66 & 2.62 \\
4 & 1.44 & 3.04 & 1.44 & 2.52 & 1.04 & 1.44 & 1.44 & 2.60 \\
5 & 1.11 & 2.22 & 1.11 & 2.00 & 2.11 & 2.67 & 1.67 & 2.67 \\
6 & 1.06 & 3.33 & 1.06 & 1.89 & 1.11 & 1.28 & 1.11 & 1.94 \\
7 & 0.94 & 4.35 & 0.94 & 2.59 & 0.94 & 1.29 & 0.71 & 0.94 \\
Mean & 1.29 & 2.88 & 1.19 & 2.23 & 1.31 & 1.51 & 1.16 & 2.00 \\
SD & 0.24 & 0.71 & 0.27 & 0.30 & 0.50 & 0.55 & 0.40 & 0.66 \\
Group 2 & & & & & & & \\
1 & 2.09 & 4.04 & 1.83 & 3.48 & 2.61 & 4.52 & 2.52 & 3.30 \\
2 & 1.79 & 6.13 & 1.70 & 4.06 & 1.79 & 2.74 & 1.60 & 2.17 \\
3 & 3.05 & 4.69 & 3.20 & 5.08 & 3.05 & 4.77 & 3.05 & 3.98 \\
4 & 1.89 & 4.39 & 1.89 & 4.62 & 1.89 & 3.56 & 1.59 & 3.41 \\
5 & 1.90 & 5.50 & 1.90 & 3.70 & 2.50 & 6.30 & 2.70 & 4.20 \\
6 & 1.43 & 4.11 & 1.43 & 3.57 & 1.43 & 5.63 & 1.52 & 3.57 \\
7 & 1.48 & 5.22 & 0.87 & 2.43 & 2.61 & 6.26 & 2.26 & 4.87 \\
Mean & 1.95 & 4.87 & 1.83 & 3.85 & 2.27 & 4.82 & 2.18 & 3.64 \\
SD & 0.50 & 0.72 & 0.65 & 0.79 & 0.53 & 1.25 & 0.57 & 0.78 \\
\hline
\end{tabular}

New baseline flows were measured before each intervention. SD, Standard deviation.

Table III. Vasodilatory response and nitric oxide release after a l-minute infusion of bradykinin $\left(10^{-6}\right.$ mol/L) before and after cardioplegic arrest

\begin{tabular}{|c|c|c|c|c|}
\hline \multirow[b]{2}{*}{ Heart } & \multicolumn{2}{|c|}{$\%$ baseline $C B F$} & \multicolumn{2}{|c|}{ NO release $(\mathrm{nmol} / \mathrm{min})$} \\
\hline & Prearrest & Postarrest & Prearrest & Postarrest \\
\hline \multicolumn{5}{|c|}{ Group 1 (UW cardioplegia) } \\
\hline 1 & 175 & 111 & 84 & -34 \\
\hline 2 & 165 & 100 & 34 & -27 \\
\hline 3 & 185 & 139 & -38 & -42 \\
\hline 4 & 211 & 91 & 195 & 12 \\
\hline 5 & 200 & 125 & 150 & -69 \\
\hline 6 & 316 & 118 & 148 & -22 \\
\hline 7 & 463 & 137 & 98 & -44 \\
\hline Mean \pm SEM & $245 \pm 41$ & $117 \pm 7$ & $96 \pm 30$ & $-32 \pm 9$ \\
\hline \multicolumn{5}{|c|}{ Group 2 (Blood cardioplegia) } \\
\hline 1 & 193 & 173 & & \\
\hline 2 & 34 & 152 & & \\
\hline 3 & 154 & 156 & & \\
\hline 4 & 234 & 188 & & \\
\hline 5 & 289 & 252 & & \\
\hline 6 & 288 & 394 & & \\
\hline 7 & 353 & 240 & & \\
\hline Mean \pm SEM & $265 \pm 28$ & $222 \pm 32$ & & \\
\hline
\end{tabular}

Nitric oxide release was not measured in the blood cardioplegia group. $C B F$, Coronary blood flow; $N O$, nitric oxide; $S E M$, standard error of the mean.

in hearts protected with blood cardioplegia. The addition of calcium to UW solution resulted in $100 \%$ functional recovery at left atrial pressures of 3,6 , and $9 \mathrm{~mm} \mathrm{Hg}$, and 93\% recovery at a left atrial pressure of $12 \mathrm{~mm} \mathrm{Hg}$. The functional recovery obtained with UW solution or UW solution with added calcium was significantly greater than that obtained with conventional blood cardioplegia. $^{32}$

Despite UW solution's impressive performance, both clinically in transplantation and experimentally for neonatal myocardial protection, increased understanding of the importance of coronary endothelial function and rec- 


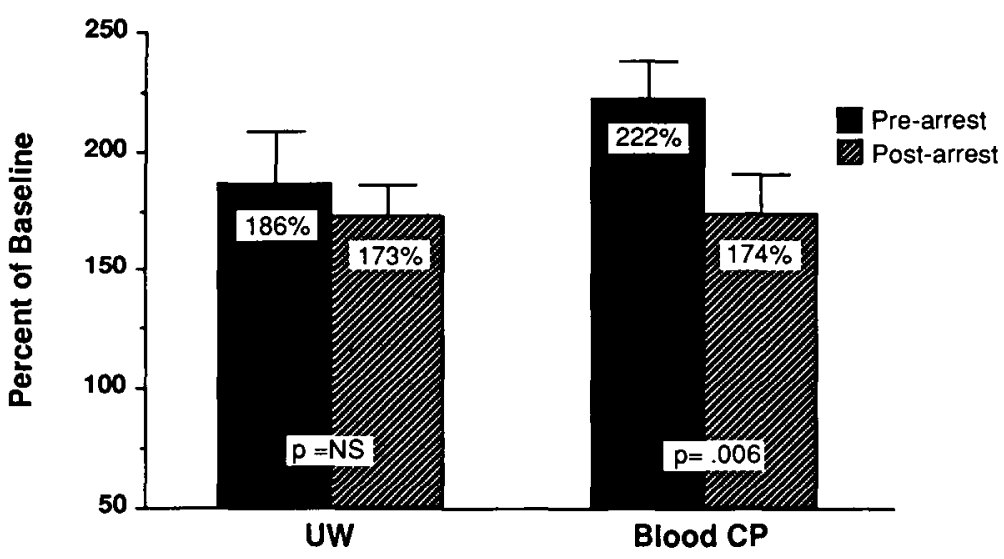

Fig. 2. Endothelium-independent coronary blood flow. There was no significant difference in vasodilatory response to nitroprusside before and after arrest in hearts protected with UW solution (group 1). There was a small but significant decrease in vasodilatation in hearts protected with blood cardioplegia (group 2). NS, Not significant; Blood $C P$, blood cardioplegia.

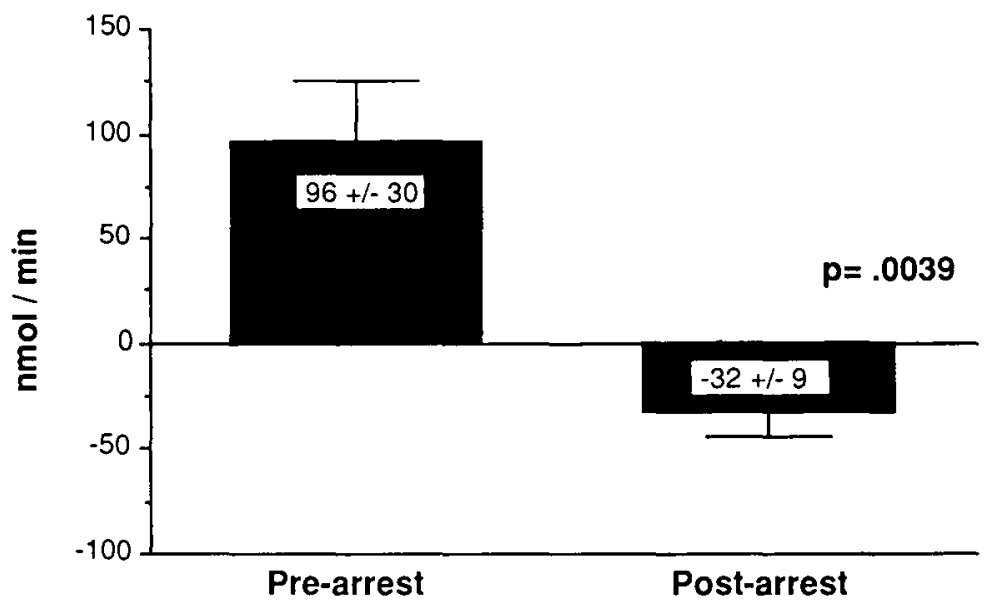

Fig. 3. Nitric oxide release before and after cardioplegic arrest with $U W$ solution. There was a significant increase in nitric oxide release in response to bradykinin infusion before arrest in group 1. After arrest with UW solution, there was complete loss of nitric oxide release $(p=0.0039)$, which correlated with observed lack of vasodilatation.

ognition that high potassium concentrations may be harmful to endothelium have raised concerns regarding the safety of UW solution. ${ }^{19-22,23}$ Mankad, Chester, and Yacoub $^{22}$ have previously showed that preservation with cardioplegic solutions containing a potassium concentration as low as $30 \mathrm{mEq} / \mathrm{L}$ can abolish the endotheliumdependent vasodilatory response to 5-hydroxytryptophan. When the potassium concentration was reduced to $20 \mathrm{mEq} / \mathrm{L}$, the 5-hydroxytryptophan-induced endothelium-dependent vasodilatory response was maintained.

Saldanha and Hearse ${ }^{21}$ demonstrated loss of coronary vasodilatation in response to 5-hydroxytryplophan in rat hearts after a 30-minute continuous infusion of cardioplegic solution containing a potassium concentration of 25
$\mathrm{mEq} / \mathrm{L}$. Other investigators ${ }^{18-20,33,34}$ have also shown functional endothelial injury and platelet deposition after infusion of hyperkalemic cardioplegic solution.

Cartier and colleagues ${ }^{23}$ did early work looking specifically at the effect of UW solution on endothelial function, in which either perfusion with or perfusion and storage with UW solution resulted in loss of endothelium-dependent vasodilatation. Nitric oxide was not measured in that study, however. In this study, we clearly demonstrated significant impairment in endothelium-dependent vasodilatation, which is attributable to failure of nitric oxide release by the endothelium after infusion of UW cardioplegic solution.

Mankad, Slavik, and Yacoub ${ }^{35}$ recently concluded 
Table IV. Vasodilatory response to 1-minute infusion of sodium nitroprusside $\left(10^{-6} \mathrm{~mol} / \mathrm{L}\right)$ before and after cardioplegic arrest as a percentage of baseline coronary blood flow

\begin{tabular}{ccc}
\hline Heart & Prearrest & Postarrest \\
\hline Group I (UW cardioplegia) & & \\
1 & 145 & 175 \\
2 & 152 & 230 \\
3 & 179 & 159 \\
4 & 175 & 181 \\
5 & 170 & 160 \\
6 & 225 & 175 \\
7 & 260 & 134 \\
Mean \pm SEM & $186 \pm 16$ & $173 \pm 11$ \\
Group 2 (Blood cardioplegia) & \\
1 & 190 & 131 \\
2 & 238 & 135 \\
3 & 158 & 131 \\
4 & 244 & 214 \\
5 & 195 & 156 \\
6 & 250 & 236 \\
7 & 282 & 216 \\
Mean \pm SEM & $222 \pm 16$ & $174 \pm 18$ \\
\hline
\end{tabular}

$S E M$, Standard error of the mean.

that $\mathrm{UW}$ solution results in endothelial dysfunction when infused at $15^{\circ} \mathrm{C}$ but not when infused at $4^{\circ} \mathrm{C}$ or $10^{\circ} \mathrm{C}$. Dysfunction was determined by both impaired vasodilatory response to 5-hydroxytryptamine and increased basal coronary artery resistance. ${ }^{35}$ Although impaired release of endothelium-derived relaxing factor has been postulated as the cause of impaired vasodilatation after high-potassium cardioplegia, nitric oxide release has not been measured in previous studies.

Cullen, Haworth, and Warren ${ }^{34}$ attempted to measure in vitro changes in levels of endothelium-derived relaxing factor in response to incubation of pulmonary endothelial cells in UW solution. Surprisingly, release of endothelium-derived relaxing factor in response to bradykinin was maintained in cells incubated with UW solution $(\mathrm{K}=$ $140 \mathrm{mEq} / \mathrm{L}$ ) or other crystalloid solutions with potassium concentrations of 80 to $107 \mathrm{mEq} / \mathrm{L}$ but was impaired after incubation with a blood cardioplegic solution with a potassium concentration of only $6.8 \mathrm{mEq} / \mathrm{L}$. Cullen, Haworth, and Warren ${ }^{34}$ attributed the loss in release of endothelium-derived relaxing factor in the blood cardioplegia-incubated cells to the acidity of the solution and not to the potassium concentration. The discrepancy between these findings and those of ourselves and others may be related to the use of isolated cells rather than an intact model, the use of pulmonary rather than coronary endothelial cells, and the basic pH (7.6) of the blood cardioplegic solution used in our investigation.
The duration of endothelial dysfunction after high-potassium cardioplegia is unknown, but certainly this duration influences the importance of our findings. Vanhoute has found that 4 weeks after endothelial injury regenerated endothelium, although structurally normal, has a blunted response to vasodilatory stimuli. ${ }^{16}$ Others have demonstrated a hypercontractile state and loss of vasodilatory response even 8 weeks after endothelial injury. Cartier and colleagues ${ }^{36}$ have shown incomplete recovery of endothelium-dependent vasodilatation and an increased vasoconstrictive potential 8 weeks after endothelial injury, despite the presence of histologically intact endothelial cells.

The significance of impaired endothelium-dependent vasodilatation is uncertain. The endothelium's increased predisposition toward vasospasm and inability to release nitric oxide results in platelet deposition ${ }^{37-39}$ and an increased propensity toward thrombosis. Treatment with arachidonic acid inhibitors such as indomethacin or with calcium-channel blockers has not been effective in modifying the early loss of vasodilatory reserve. ${ }^{40}$

The importance of nitric oxide release in regulation of basal coronary tone has been demonstrated in several investigations. ${ }^{11,41,42}$ Endothelium-dependent vasodilatation has been shown to affect regional distribution of myocardial perfusion, specifically increasing subendocardial perfusion and increasing the subendocardial/subepicardial blood flow ratio. ${ }^{41}$ Impaired autoregulation may affect the response to certain hemodynamic stresses such as pressure overload, where failure to increase subendocardial blood flow could lead to ischemia. Mankad, Slavik, and Yacoub ${ }^{35}$ demonstrated basal increase in coronary vascular resistance after infusion of UW solution at $15^{\circ} \mathrm{C}$ but not at $4^{\circ} \mathrm{C}$ or $10^{\circ} \mathrm{C}$. Loss of endothelium-dependent vasodilatation has been correlated with atherosclerosis. ${ }^{16,43}$ This may be important with regard to the development of accelerated graft atherosclerosis in the transplanted heart, or to the early onset or progression of coronary artery disease if UW solution is used for myocardial protection in nontransplant cardiac operations.

\section{Summary}

In this study and in others, ${ }^{17,} 19-23$ it has been demonstrated that high-potassium cardioplegic solutions such as UW solution result in functional impairment of coronary endothelium. After multidose cardioplegia with UW solution, there is a failure of endothelium-dependent vasodilatation. This loss of vasodilatory reserve corresponds with failure of nitric oxide release by the endothelium. However, the duration of this functional deficit and both the short- and long-term effects are unknown. Fur- 
ther studies are necessary to determine the significance of these findings and to evaluate the long-term effects of UW solution on the coronary endothelium.

\section{REFERENCES}

1. Makad PS, Severs NJ, Lacno DR, Rothery S, Yacoub MH. Superior qualities of University of Wisconsin solution for endothelial vivo preservation of the pig heart. J THORAC Cardiovasc Surg 1992;104:229-40.

2. Ko W, Zelano JA, Lazzaro R, et al. Optimal storage period for extended heart preservation with the University of Wisconsin solution: a study of the left ventricular pressurevolume relationship. J Cardiovasc Surg (Torino) 1992;33: 204-10.

3. Ko W, Zelano JA, Lazzaro R, et al. Superiority of the University of Wisconsin solution over simple crystalloid for extended heart preservation: a study of the left ventricular pressure-volume relationship. J THORAC CARDIOvaSC SURG 1992;103:580-92.

4. Jeevanadam V, Barr ML, Auter JS, et al. University of Wisconsin solution for human donor heart preservation: initial clinical experience. Ann Thorac Surg 1991;52: 1213-6.

5. Stein DG, Permut LC, Drinkwater DC, et al. Complete functional recovery after 24-hour heart preservation with University of Wisconsin solution and modified reperfusion. Circulation 1991;84(5 Suppl):III316-23.

6. Stein DG, Drinkwater DC, Laks H, et al. Cardiac preservation in patients undergoing transplantation: a clinical trial comparing University of Wisconsin solution and Stanford solution. J THORAC CARDIOVASC SURG 1991;102:65765.

7. Bull C, Cooper J, Stark J. Cardioplegic protection of the child's heart. J THORAC CARDIOVASC SURG 1984;88:28793.

8. Watanabe H, Yokosawa T, Eguchi S, Imai S. Functional and metabolic protection of the neonatal myocardium from ischemia: insufficient protection by cardioplegia. J THORAC Cardiovasc Surg 1989;97:50-8.

9. Avkiran M, Hearse DJ. Protection of the neonatal myocardium during global ischemia: Is crystalloid cardioplegia effective in the immature myocardium? J THORAC CARDIOVASC SURG 1989;97:220-8.

10. Corno AF, Bethencourt DM, Laks $\mathrm{H}$, et al. Myocardial protection in the neonatal heart. J THORAC CARDIOVASC SURG 1987;93:163-72.

11. Richard V, Berdeaux A, Drieu la Rochelle C, Giudicelli JF. Regional coronary haemodynamic effects of two inhibitors of nitric oxide synthesis in anaesthetized, open-chest dogs. Br J Pharmacol 1991;104:59-64.

12. Pelc LR, Garancis JC, Gross GJ, Warltier DC. Alteration of endothelium-dependent distribution of myocardial blood flow after coronary occlusion and reperfusion. Circulation 1990;81:1928-37.

13. Kelm M, Shrader J. Control of coronary vascular tone by nitric oxide. Circ Res 1990;66:1561-75.
14. Parent $R$, Paré $R$, Lavallé $M$. Contribution of nitric oxide to dilation of resistance coronary vessels in conscious dogs. Am Physiol Soc 1992;262:H10-6.

15. Amezcua JL, Palmer RMJ, de Souza BM, Moncada S. Nitric oxide synthesized from 1-arginine regulates vascular tone in the coronary circulation of the rabbit. Br J Pharmacol 1989;97:1119-24.

16. Shimokawa H, Vanhoute PM. Impaired endothelium-dependent relaxation to aggregating platelets and related vasoactive substances in porcine coronary arteries in hypercholesterolemia and atherosclerosis. Circ Res 1989;64:90014.

17. Shimokawa H, Aarhus LL, Vanhoutte PM. Porcine coronary arteries with regenerated endothelium have a reduced endothelium-dependent responsiveness to aggregating platelets and serotonin. Circ Res 1987;61:256-70.

18. Carpentier S, Murawsky M, Carpentier A. Cytotoxicity of cardioplegic solutions: evaluation by tissue culture. Circulation 1981;64(2 Pt 2):II90-5.

19. Follette DM, Buckberg GD, Mulder DG, Fonkalsrud RW. Deleterious effects of crystalloid cardioplegic solutions on arterial endothelial cells. Surg Forum 1980;31:253-5.

20. Harjula A, Mattila S, Mattila I, et al. Coronary endothelial damage after crystalloid cardioplegia. J Cardiovasc Surg (Torino) 1984;25:147-52.

21. Saldanha C, Hearse DJ. Coronary vascular responsiveness to 5-hydroxytryptamine before and after infusion of hyperkalemic crystalloid cardioplegic solution in the rat heart: possible evidence of endothelial damage. J THORAC CARDIOVASC SuRg 1989;98:783-7.

22. Mankad PS, Chester AH, Yacoub MH. Role of potassium concentration in cardioplegic solutions in mediating endothelial damage. Ann Thorac Surg 1991;51:89-93.

23. Cartier R, Hollman C, Dagnais F, Bulluran J, Pellerin M, Leclerc $Y$. University of Wisconsin preservation solution induces endothelial functional damage during long term storage in the isolated rat heart. Ann Thorac Surg 1993; 55:50-5.

24. Jeevanandam V, Barr ML, Auteri JS, et al. University of Wisconsin solution versus crystalloid cardioplegia for human donor heart preservation: a randomized blinded prospective clinical trial. J THORAC CARDIovasc Surg 1992;103:194-9.

25. Braman RS, Hendrix SA. Nanogram nitrite and nitrate determination in environmental and biological materials by vanadium (III) reduction with chemiluminescence detection. Anal Chem 1989;61:2715-8.

26. Bush PA, Gonzalez NE, Griscavage JM, Ignarro LJ. Nitric oxide synthase from cerebellum catalyzes the formation of equimolar quantities of nitric oxide and citrulline from l-arginine. Biochem Biophys Res Commun 1992;185: 960-6.

27. Byrns R, Ignarro L. Application of chemiluminescence detection to the measurement of nitric oxide as its oxidation products nitrite and nitrate in biological tissues [In press].

28. Rosenkranz ER, Okamato F, Buckberg GD, et al. Safety of prolonged aortic clamping with blood cardioplegia. III. 
Aspartate enrichment of glutamate-blood cardioplegia in energy-depleted hearts after ischemic and reperfusion injury. J Thorac Cardiovasc Surg 1986;91:428-34.

29. Allen BS, Okamato F, Buckberg GD, et al. Studies of controlled reperfusion after ischemia. IV. Immediate functional recovery after six hours of regional ischemia by careful control of conditions of reperfusion and composition of reperfusate. J THORAC CARDIOVASC SURG 1986;92:621-6.

30. Pearl JM, Drinkwater DC, Laks H, Capouya ER, Gates RN. Leukocyte-depleted reperfusion of transplanted human hearts: a randomized, double-blind clinical trial. J Heart Lung Transplant 1992;11:1082-92.

31. Pearl JM, Drinkwater DC, Laks H, Stein DG, Capouya ER, Bhuta S. Leukocyte-depleted reperfusion of transplanted human hearts prevents ultrastructural evidence of reperfusion injury. J Surg Res 1992;52:298-308.

32. Pearl JM, Laks H, Drinkwater DC, et al. Normocalcemic blood or crystalloid cardioplegia provides superior neonatal myocardial protection over low-calcium cardioplegia. J Thorac Cardiovasc Surg 1993;105:201-6.

33. Rosenbaum D, Levitsky S, Silverman N, et al. Cardioplegia does not prevent reperfusion injury induced by intracoronary platelet deposition. Circulation 1983;68(3 Pt 2): II 102-6.

34. Cullen S, Haworth SG, Warren JD. Donor organ preservation fluids differ in their effect on endothelial cell function. J Heart Lung Transplant 1991;10:999-1003.

35. Mankad P, Slavik Z, Yacoub M. Endothelial dysfunction caused by University of Wisconsin preservation solution in the rat heart: the importance of temperature. J THORAC Cardiovasc Surg 1992;104:1618-24.

36. Cartier R, Pearson P, Pyng JL, Schaff H. Time course and extent of recovery of endothelium-dependent contractions and relaxations after direct arterial injury. J THORAC CARDIOVASC SURG 1991;102:371-7.

37. Azuma H, Ishikawa M, Sekizaki S. Endothelium-dependent inhibition of platelet aggregation. $\mathrm{Br} \mathrm{J}$ Pharmacol 1986;88:411-5.

38. Furlong B, Henderson AH, Lewis MJ, Smith JA. Endothelium-derived relaxing factor inhibits in vitro platelet aggregation. Br J Pharmacol 1987;90:687-92.

39. Sneddon JM, Vane JR. Endothelium-derived relaxing factor reduces platelet adhesion to bovine endothelial cells. Proc Natl Acad Sci U S A 1988;85:2800-4.

40. Mehta JL, Nichols WW, Donnelly WH, Lawson DL, Saldeen TGP. Impaired canine coronary vasodilator response to acetylcholine and bradykinin after occlusionreperfusion. Circ Res 1989;64:43-54.

41. Chu A, Chambers DE, Lin CC, Kuehl WD, Cobb FR. Nitric oxide modulates epicardial coronary basal vasomoter tone in awake dogs. Am Physiol Soc 1992;262:H17-23.

42. Jones LF, Brody MJ. Coronary blood flow in rats is dependent on the release of vascular nitric oxide. J Pharmacol Exp Ther 1991;260:627-31.

43. Fish DR, Nabel EG, Selwyn AP. Responses of coronary arteries of cardiac transplant patients to acetylcholine. $\mathbf{J}$ Clin Invest 1988;81:21-6. 